\title{
Long-Term Suppression of Weight Gain, Adiposity, and Serum Insulin by Central Leptin Gene Therapy in Prepubertal Rats: Effects on Serum Ghrelin and Appetite-Regulating Genes
}

\author{
ELENA BERETTA, MICHAEL G. DUBE, PUSHPA S. KALRA, AND SATYA P. KALRA
}

Department of Neuroscience, University of Florida McKnight Brain Institute, Gainesville, Florida

32610-0244, U.S.A [E.B., S.P.K.]; Department of Physiology and Functional Genomics, University of

Florida, College of Medicine, Gainesville, Florida 32610-0274, U.S.A. [M.G.D., P.S.K.]

\section{ABSTRACT}

Intracerebroventricular administration of recombinant adenoassociated virus (rAAV) encoding the rat leptin gene (rAAV-lep) to 24-d-old female and male rats suppressed postpubertal weight gain for extended periods by decreasing food consumption and adiposity, as reflected by lowered serum leptin, insulin, and FFA. Serum ghrelin levels were increased in young but not older rats. Central rAAV-lep therapy also increased energy expenditure through nonshivering thermogenesis in younger rats as shown by expression of uncoupling protein mRNA in brown adipose tissue. The sustained decrease in appetite seemingly resulted from attenuation of appetite-stimulating neuropeptide $\mathrm{Y}$ and enhancement of appetite-inhibiting melanocortin signalings in the hypothalamus. Neither the onset of pubertal sexual maturation nor reproductive cyclicity in adult female rats was affected by the sustained reduction in energy consumption and weight gain. These findings demonstrate that central leptin gene therapy in prepubertal rats is a novel therapy to control postpubertal weight gain, adiposity, and hyperinsulinemia for extended periods. (Pediatr Res 52: 189-198, 2002)
rAAV, adeno-associated virus

BAT, brown adipose tissue

BW, body weight

ARN, appetite-regulating network

lep, leptin

icv, intracerebroventricular

NPY, neuropeptide Y

FI, food intake

UCP1, uncoupling protein 1

POMC, proopiomelanocortin

AGRP, agouti-related peptide

$\boldsymbol{\alpha}$-MSH, $\alpha$-melanocortin stimulating hormone

GFP, green florescent protein

CSF, cerebrospinal fluid

ARC, arcuate nucleus

PF, pair-feeding

PVN, paraventricular nucleus
Considerable attention has focused recently on the role of leptin in the hypothalamic integration of energy homeostasis $(1,2)$. Although produced primarily by white adipose tissue and released into the general circulation, other tissues, including the hypothalamus, have been reported to produce leptin for paracrine/autocrine action $(3,4)$. Experimental evidence shows that peripheral leptin is transported across the blood-brain barrier to the hypothalamus to regulate $\mathrm{BW}$ by dual action $(1,5)$. Leptin restrains food intake

Received December 3, 2001; accepted March 28, 2002.

Correspondence: Satya P. Kalra, Ph.D., Department of Neuroscience, University of Florida McKnight Brain Institute, P.O. Box 100244, Gainesville, FL 32610-0244, U.S.A.; e-mail: skalra@ufbi.ufl.edu

Supported by Grants DK37272, HD 08634n, and NS 32727 from the National Institutes of Health.

DOI: 10.1023/01.PDR.0000023496.70201.8E by modulating the ARN (5) and, simultaneously, it enhances the nonshivering thermogenic energy expenditure by $\operatorname{BAT}(6,7)$. However, resistance to peripheral leptin develops readily in rodents and humans with aging (8-10) and after consumption of calorie-rich diets (11-15), each culminating in increased fat deposition and obesity and a rise in circulating leptin levels in direct proportion to fat depots. Because leptin levels in CSF do not increase in proportion to the peripheral concentrations (16-18) and leptin administered centrally is effective despite elevated peripheral leptin in diet-induced obese rodents (19), defective leptin transport to central sites may be a causal factor in the loss of leptin control. Consequently, newer experimental approaches have recently been explored either to circumvent the impaired leptin transport or to overcome leptin insufficiency at hypothalamic sites (20). 
Gene transfer by rAAV vectors to correct deficiencies underlying CNS diseases has been extensively investigated in rodents (21-23). The feasibility of generating rAAV vectors at high titers for long-term transgene expression in nondividing cells without eliciting an immunogenic response is the distinct advantages of rAAV over other viral vectors $(22,23)$. We generated a rAAV vector encoding leptin cDNA (rAAV-lep) and evaluated its efficacy in leptin-deficient $o b / o b$ mice and in normal adult rats $(10,15,24,25)$. Results demonstrated that a single icv injection of rAAV-lep increased leptin transgene expression in the hypothalamus, leading to a sustained reduction in weight gain and adiposity in rats consuming either regular rat chow or a high-fat diet. A drastic reduction in hyperleptinemia and hyperinsulinemia in conjunction with normoglycemia was noted in these rats. Reduction in energy consumption and/or increased thermogenic energy expenditure, as indicated by enhanced uncoupling protein-1 mRNA in the BAT $(6,7)$, accounted for the sustained loss of adiposity. An evaluation of the leptin transgene action on hypothalamic ARN showed a decrease in the appetite-stimulating NPY concurrent with an increase in inhibitory melanocortin signaling (24).

Obesity presents a worldwide health problem as it is a major cause of hypertension, stroke, non-insulin-dependent diabetes, and increased morbidity (26). A recent census showed a rise in pediatric obesity, with large numbers of overweight children and adolescents who are at risk to become overweight adults and face similar health risks (27). Available pharmacologic approaches are cumbersome, transiently effective, and require repeated treatments. Because a single administration of rAAVlep in adult rats produced weight reduction and prevented obesity for 6 mo duration of the experiment (25), the primary aim of this undertaking was to ascertain whether central leptin gene therapy will be effective in maturing rats for an extended period. The first objective of this study was to assess the long-term efficacy of central rAAV-lep therapy in prepubertal rats on FI, weight gain, and adiposity during the pubertal and postpubertal periods. Because hyperinsulinemia is closely associated with obesity $(1,2,28,29)$, the second objective was to evaluate the long-term effects of central leptin overexpression on circulating insulin and glucose levels.

Our previous studies in adult rats showed that leptin transgene expression in the hypothalamus markedly increased thermogenic energy expenditure as indicated by increased BAT UCP1 mRNA expression $(24,25)$. Our third objective was to determine whether rAAV-lep therapy started prepubertally would sustain increased energy expenditure into adulthood. As leptin injections in adult rats down-regulate orexigenic NPY and AGRP and up-regulate the anorexigenic peptide $\alpha$-MSH, derived from the $P O M C$ gene $(1-3,30)$, the fourth objective was to evaluate whether leptin overexpression in the hypothalamus would exert sustained effects on these two functionally opposing, appetite-regulating, peptidergic systems in the hypothalamus.

Ghrelin, a peptide produced in the stomach (31), has recently been shown to stimulate feeding by increasing NPY release in the hypothalamus (32-34). Ghrelin secretion is increased after fasting and this increment may play a role in stimulating appetite (34). Our fifth objective was to analyze circulating ghrelin levels in rats displaying reduced food intake in response to hypothalamic leptin-overexpression.

Finally, a secondary objective of this study was to evaluate neuroendocrine effects of central rAAV-lep therapy in noninvasive manner so as not to compromise these five major objectives. There is evidence that leptin may be involved in the neuroendocrine regulation of sexual maturation and reproductive cycles $(35,36)$. Administration of leptin prepubertally was reported by some but not all investigators to advance the onset of puberty (35-37). A delay in sexual maturation in response to drastic caloric restriction prepubertally was prevented by leptin administration (37-40). Similarly, fasting and severe caloric restriction in adult rodents have been shown to interrupt estrous cycles $(41,42)$. The sixth objective of this investigation was to evaluate the impact of reduced voluntary caloric intake produced by prepubertal central leptin gene therapy on the onset of puberty and postpubertal estrous cycle patterns, the evaluation parameters of which are noninvasive.

\section{MATERIALS AND METHODS}

\section{Experimental Animals}

Twenty-one-day-old female and male Sprague Dawley rats (35-60 g) were purchased from Harlan Sprague Dawley (Indianapolis, IN, U.S.A.) and housed individually in a temperature- $\left(22-25^{\circ} \mathrm{C}\right)$ and light-controlled $(14 \mathrm{~h}$ light, $10 \mathrm{~h}$ dark), specific-pathogen-free environment. Animals were fed standard rat chow ad libitum (Teklad, Madison, WI, U.S.A.) and water was available at all times. The experimental protocols were approved by the Institutional Animal Care and Use Committee.

\section{Construction and Packaging of rAAV Vectors}

The rAAV-vectors used in this study were constructed at the University of Florida Gene Therapy Center. Briefly, the vector pTR-CBA-Ob EcoRI fragment of pCR-rOb (a gift of Dr. Roger H. Unger, Southwestern Medical School, Dallas, TX, U.S.A.) containing rat leptin cDNA was subcloned into rAAV vector plasmid pAAV $\beta$ GEnh after deletion of the EcoRI fragment carrying $\beta$-glucuronidase cDNA sequence. Vectors were packaged, purified, concentrated, and titered essentially as described previously $(10,24,25,43)$. The titer of rAAV-CBA-Ob vector, hereafter referred to as rAAV-lep, was $2.3 \times 10^{13}$ physical particles $/ \mathrm{mL}$. The ratio of physical-to-infectious particles was $<100$. The control vector rAAV-UF5, encoding the GFP (43), was similarly constructed. The titer of the rAAVUF5 used was $3 \times 10^{13}$ physical particles $/ \mathrm{mL}$.

\section{Experimental Design}

To evaluate the effects of icv injection of rAAV-lep on BW, FI and metabolic hormones in the blood, 22-d-old rats were anesthetized with an i.p. injection of ketamine/xylazine (ketamine $100 \mathrm{mg} / \mathrm{kg} \mathrm{BW}+$ xylazine $15 \mathrm{mg} / \mathrm{kg} \mathrm{BW}$ ) and stereotaxically implanted with a permanent cannula in the third cerebroventricle, and CSF efflux served as an indicator of accuracy of cannula placement $(24,25)$. 
Experiment 1: long-term study. Rats bearing icv cannula were divided into two weight-matched groups (eight to 10 rats per group) on d 24 and injected icv $(3 \mu \mathrm{L})$ with either rAAV-UF5 (control, $9 \times 10^{10}$ particles) or rAAV-lep $(6.9 \times$ $10^{10}$ particles). Selection of these titers was based on our previous studies $(24,25)$. A third group of weight-matched rats consisting of unoperated, untreated rats $(n=8)$ was monitored in parallel. BW and 24-h FI were recorded before the injection and twice a week thereafter for $294 \mathrm{~d}$. To determine the timing of sexual maturation in female rats, vaginal opening was assessed by daily observation from d 24 onward. After vaginal opening, vaginal cytology of each female was recorded (4446) to determine the numbers of estrous cycle and cycle length during d 54-70, 120-146, 186-240, and 240-270.

Experiment 2: short-term studies. In the first experiment, female rats were divided into two weight-matched groups (seven to nine rats per group) and injected icv ( $3 \mu \mathrm{L})$ with either rAAV-UF5 or rAAV-lep, as described in experiment 1. The timing of vaginal opening and estrous cycle length between d 54-70 was assessed as described in experiment 1 . BW and 24-h FI were monitored twice a week for $89 \mathrm{~d}$ postinjection. Additionally, there were three control groups: 1) untreated, unoperated rats $(n=8) ; 2)$ sham-operated rats $(n=7)$; and 3) unoperated, rats pair-fed to the amount consumed by rats receiving rAAV-lep $(n=7)$. In the second experiment, male rats were divided into two weight-matched groups (seven to 11 rats per group), and injected icv either with rAAV-UF5 or rAAV-lep as described in experiment 1 . Control groups consisted of sham-operated animals $(n=8)$, unoperated, untreated rats $(n=6)$, and unoperated, untreated rats $(n=7)$ pair-fed to the amount consumed by rats receiving rAAV-lep treatment. BW and 24-h FI were monitored once a week for $111 \mathrm{~d}$ postinjection.

At the end of the experiments, rats were killed between 0900 and $1200 \mathrm{~h}$. Brain and BAT tissues were dissected out and rapidly frozen at $-80^{\circ} \mathrm{C}$. Serum from trunk blood was collected and stored at $-20^{\circ} \mathrm{C}$ until analyses.

\section{Analyses}

RT-PCR. To confirm hypothalamic leptin mRNA expression, hypothalami from rAAV-lep- and rAAV-UF5-injected and untreated rats ( $n=4$ per group) were dissected from the brain on d 294 postinjection (long-term study, experiment 1). Total RNA was extracted using RNA STAT 60 RNA isolation kit (Tel-Test Inc., Friendswood, TX, U.S.A.). First-strand cDNA was obtained by using an RNA PCR kit (Applied Biosystems, Foster City, CA, U.S.A.) and reverse-transcriptase PCR for leptin mRNA was conducted as previously described $(24,25)$. The relative values of mRNA levels were derived from comparison of the intensities of the target and simultaneously run internal controls (cyclophilin). All PCR products were run on a single gel to control for inter-gel variation.

Analyses of hormones and metabolic variables. Serum leptin and insulin levels were measured in duplicate using rat leptin and insulin RIA kits from Linco Research Inc. (St. Charles, MO, U.S.A.). The assay sensitivity for leptin was 0.5 $\mathrm{ng} / \mathrm{mL}$ and the range of detection was between 0.5 and 50 $\mathrm{ng} / \mathrm{mL}$. The assay sensitivity for the insulin assay was 0.1 $\mathrm{ng} / \mathrm{mL}$ and the range of detection was between 0.1 and 10 $\mathrm{ng} / \mathrm{mL}$. Serum glucose was measured using Trinder, a Sigma Chemical (St. Louis, MO, U.S.A.) diagnostic glucose reagent based on a quantitative, colorimetric, enzymatic reaction read at $505 \mathrm{~nm}$. Serum FFA levels were measured using an ACS (acyl-CoA synthetase)-ACOD (acyl-CoA oxidase) method (NEFA C kit, Wako Chemicals USA, Richmond, VA, U.S.A.). Serum ghrelin levels were assayed in duplicate using a rat ghrelin RIA kit from Phoenix Pharmaceuticals (Mountain View, CA, U.S.A.). The assay sensitivity was $0.01 \mathrm{ng} / \mathrm{mL}$ and the range of detection was between 0.01 and $1.28 \mathrm{ng} / \mathrm{mL}$.

Dot blot analysis for BAT UCP-1 mRNA. BAT UCP-1 mRNA was analyzed as described $(24,25)$.

In situ hybridization. Semiquantitative analyses of gene expression of $N P Y, A G R P$, and POMC in the hypothalamic ARC of female rats $(n=3)$ in experiments 1 and 2 was conducted as previously described $(10,24)$. Twelve matched sections containing the ARC from each brain were analyzed. We estimated the relative OD (ROD), calculated as total target area multiplied by the integrated OD for AGRP, NPY, and POMC, from autoradiograms with the MCID image analysis system (Imaging Research, St. Catherines, Ontario, Canada). The background $\mathrm{OD}$ in an area adjacent to the ARC was subtracted from the target OD. The ROD of 12 sections in the same brain were averaged and expressed relative to the average ROD from the control group.

Statistical analyses. BW and FI data were analyzed using two-way repeated-measures ANOVA with time and treatment as variables. In experiment 2 , differences between the five treatment groups at each time point were compared with one-way ANOVA, followed by post hoc analysis with Tukey's multiple comparison test. All the other measures were compared either by one-way ANOVA followed post hoc with Tukey's multiple comparison test or $t$ test, as appropriate. Statistical analyses were performed using the Graph Pad Prism software version 3.00 for Windows (Graph Pad Software, San Diego, CA, U.S.A.). Significance level was set at $p<0.05$.

\section{RESULTS}

\section{Long-Term Effects of rAAV-lep Treatment in Prepubertal Rats}

Leptin mRNA in the hypothalamus. Detectable leptin mRNA expression was observed in the hypothalami of untreated and rAAV-UF5-injected control female rats at $318 \mathrm{~d}$ of age (Fig. 1). However, leptin mRNA expression at this time was significantly higher than the control values in rats injected with rAAV-lep on postnatal d 24 (experiment 1).

$\boldsymbol{B} \boldsymbol{W}$ and $\boldsymbol{F I}$. In untreated, unoperated rats and in rats treated on d 24 with control virus encoding GFP, BW gain during the prepubertal and postpubertal interval was similar (Fig. 2A); each group displayed rapid weight gain until d 124, followed by a lower rate of gain until the end of the experiment at $318 \mathrm{~d}$ of age (294 d postinjection). Although a similar biphasic pattern of weight gain was also observed in rats receiving rAAV-lep on d 24, the rate of weight gain was attenuated starting at d 30, resulting in an overall BW that was 33-35\% 
untreated RAAV-UF5 rAAV-LEP
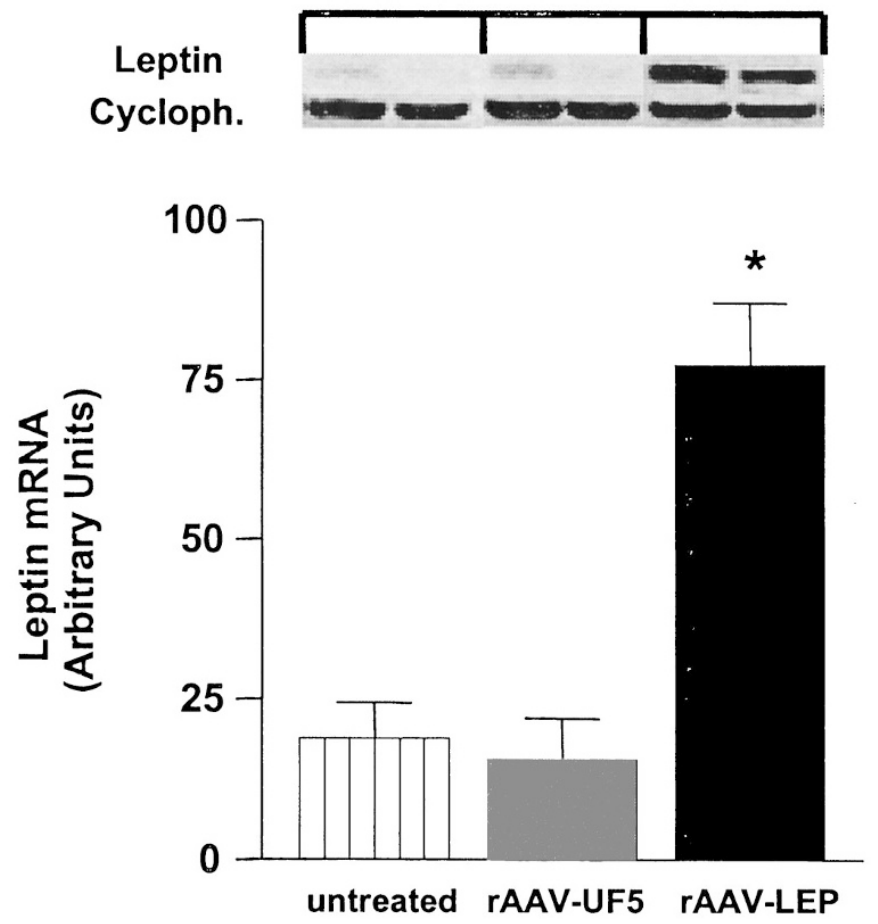

Figure 1. Analysis by reverse-transcriptase PCR analysis of hypothalamic leptin mRNA expression after $294 \mathrm{~d}$ of rAAV-lep treatment. ${ }^{*} p<0.01 v s$ rAAV-UF5 and untreated.

below that of the control groups through the course of experiment. Food consumption in the rAAV-UF5 control was also biphasic, initially a rapid exponential rise until d 54, followed by a near-plateau level of intake during the remainder of the experiment (Fig. 2B). On the other hand, daily energy consumption in response to rAAV-lep injection was reduced by $23 \%$ from that seen in rAAV-UF5 controls during the entire course of the experiment. Inadvertently, FI was not monitored in the untreated group of rats in this experiment.

Serum hormones, metabolic variables, and BAT UCP-1 $\boldsymbol{m} \boldsymbol{R} \boldsymbol{N} \boldsymbol{A}$. In association with $33-35 \%$ reduction in BW (Fig. $2 A$ ) in rAAV-lep treated rats, serum leptin levels were reduced by $90 \%$ (Fig. $2 C$ ) and serum insulin by $72-76 \%$ from those found in the two control groups (Fig. 2D). Reduction in serum insulin in rAAV-lep-treated rats was accompanied by a small decrease $(21-25 \%)$ in serum glucose levels $(p<0.05)$, but levels were still normoglycemic $(85.2 \mathrm{mg} / \mathrm{dL}$, Fig. $2 E)$. rAAV-lep treatment significantly decreased serum FFA concentrations relative to those found in control rats $(p<0.05)$; serum ghrelin levels, however, were unaffected (Table 1). UCP-1 mRNA expression in BAT was similar in controls and rAAV-lep groups (Fig. 2F).

\section{Short-Term Effects of rAAV-lep Treatment in Prepubertal Female and Male Rats}

The aim of the next short-term experiment was to determine 1) whether the effects of short-term rAAV-lep treatment (89$111 \mathrm{~d})$ were similar to those observed after $294 \mathrm{~d}$ postinjection; 2) whether icv rAAV-lep was similarly effective in prepubertal males; and 3) whether reduced food consumption alone was responsible for reduced serum hormonal and metabolic variables seen in rAAV-lep injected rats.

$\boldsymbol{B} \boldsymbol{W}$ and $\boldsymbol{F I}$. As shown in Figure 3, rAAV treatment in prepubertal females once again produced a significant reduction in BW (35-40\%) and FI (18-19\%) versus untreated and
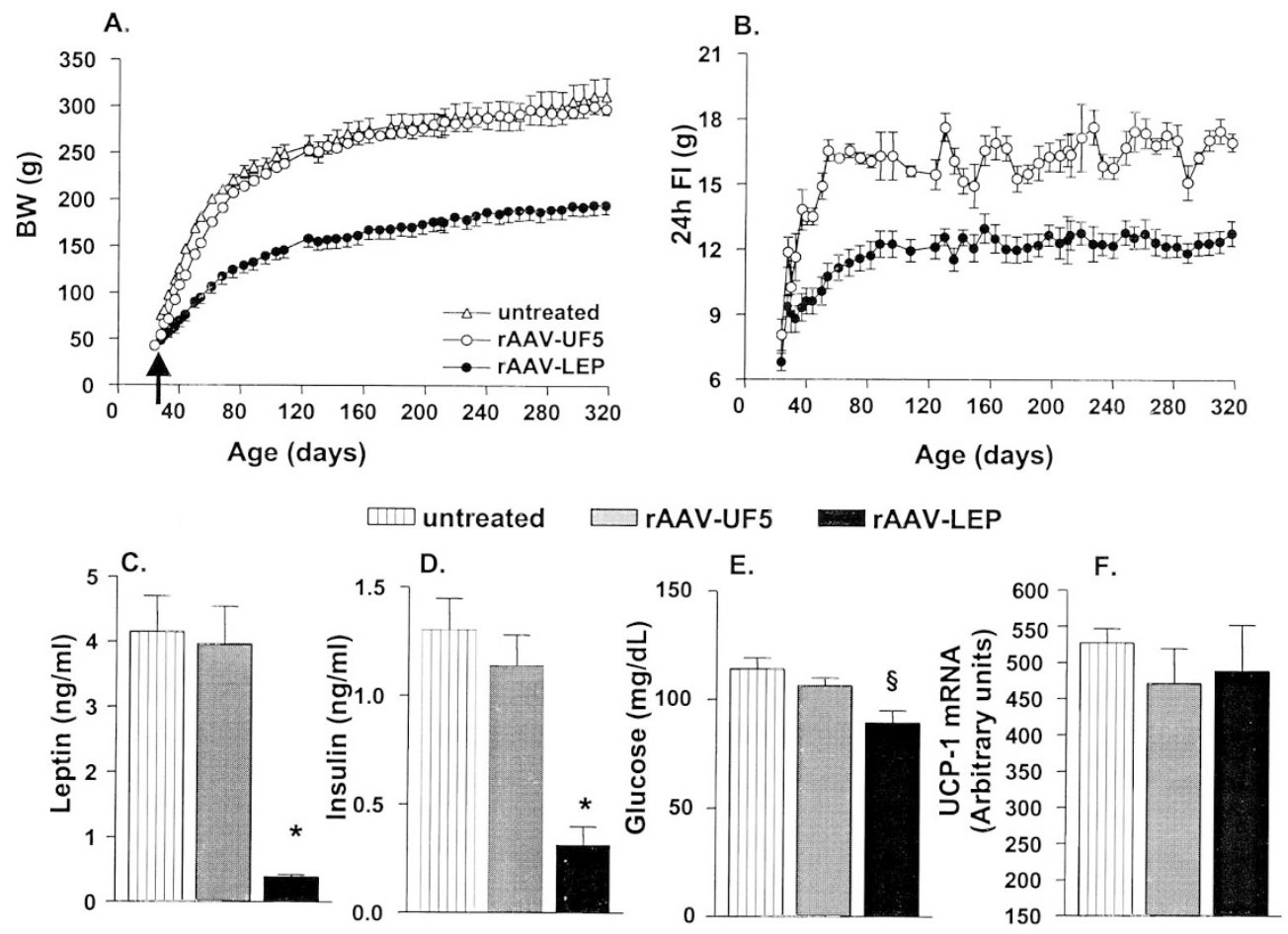

Figure 2. Effects of icv rAAV-lep injection on d 24 on BW $(A)$ and FI $(B)$ during 294 d postinjection (age $318 \mathrm{~d})$. Serum leptin $(C)$, insulin $(D)$, glucose $(E)$, and BAT UCP-1 mRNA expression $(F)$ at $294 \mathrm{~d}$ postinjection. $\S p<0.05$ and $* p<0.001 v s$ untreated and rAAV-UF5 controls. 
Table 1. Effect of rAAV-lep injection on FFAs and ghrelin levels

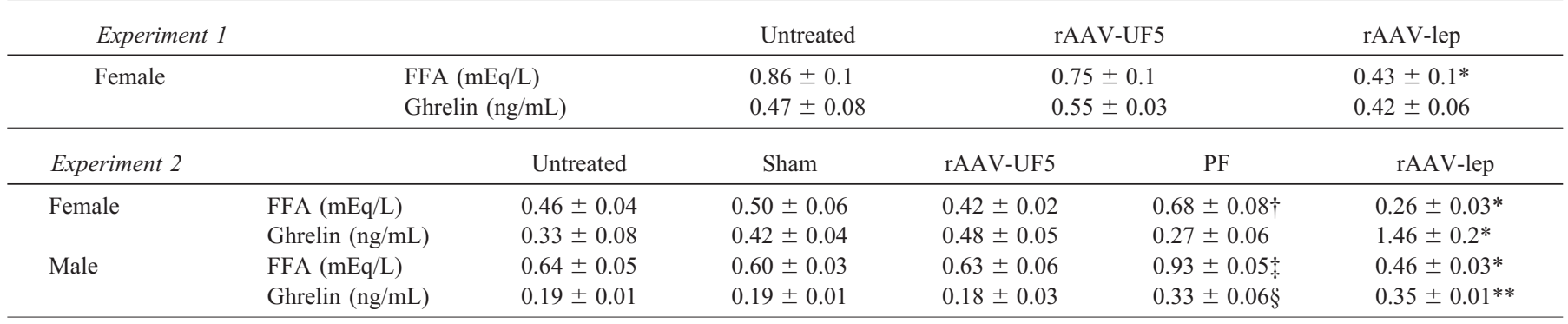

FFA and ghrelin were analyzed in the serum obtained at the end of $294 \mathrm{~d}$ (Experiment 1), $89 \mathrm{~d}$ (Experiment 2, females), and $111 \mathrm{~d}$ (Experiment 2, males) of treatment. PF, pair-fed.

${ }^{*} p<0.05 v s$ all the groups. ${ }^{* *} p<0.01 v s$ untreated, sham, rAAV-UF5, and PF groups. $\dagger p<0.05 v s$ rAAV-UF5 and rAAV-LEP. $\ddagger p<0.01 v s$ all the groups. $\S p<0.01$ vs untreated, sham, and rAAV-UF5-treated rats.

rAAV-UF5 ( $p<0.05$, Fig. $3, A$ and $B$ ), at the end of $89 \mathrm{~d}$ of observation. Likewise, rAAV-lep treatment in males (Fig. 4) decreased the weight gain and reduced daily food consumption $(17-20 \%$ versus rAAV-UF5 and untreated controls, $p<0.05$, Fig. 4, $A$ and $B$ ) during the $111 \mathrm{~d}$ duration of the experiment.

Restriction of food consumption of prepubertal female and male PF rats to the amount consumed by their counterparts, rAAV-lep treated rats, resulted in a significant reduction in weight gain (Figs. $3 A$ and $4 A$ ) but, in each instance, the weight reduction was significantly smaller than that displayed by the respective rAAV-lep-treated groups $(p<0.05)$.

Serum hormones, metabolic variables, and BAT UCP-1 $\boldsymbol{m} \boldsymbol{R} \boldsymbol{N} \boldsymbol{A}$. As in experiment 1 (Fig. 2), concomitant with the reduction in BW and FI, in female rats, serum leptin and insulin concentrations were drastically reduced in rAAV-lep group compared with controls (Fig. 3, $C$ and $D, p<0.001$ ). Interestingly, serum leptin and insulin concentrations were also reduced in PF rats compared with control rats consuming ad libitum rat chow $(p<0.001)$. However, despite the equivalent energy consumption in rAAV-lep and PF groups, serum leptin and insulin concentrations were 2-fold lower in rAAV-lep group $(p<0.05)$, thereby implying that hypothalamic leptin overexpression was responsible for the exaggerated hormonal suppression. Serum glucose levels were slightly reduced in PF and in rAAV-lep-treated rats compared with those seen in control groups, but the levels were within the normal range (Fig. 3E). Interestingly, BAT UCP-1 mRNA was enhanced by rAAV-lep treatment compared with controls and PF groups, thereby indicating increased energy expenditure through thermogenesis.

In male PF rats, $\mathrm{BW}$ reduction was also significantly smaller than that in rAAV-lep-treated rats (Fig. 4A). Similarly, rAAVlep treatment drastically reduced serum leptin and insulin concentrations compared with controls $(p<0.001)$. In con-
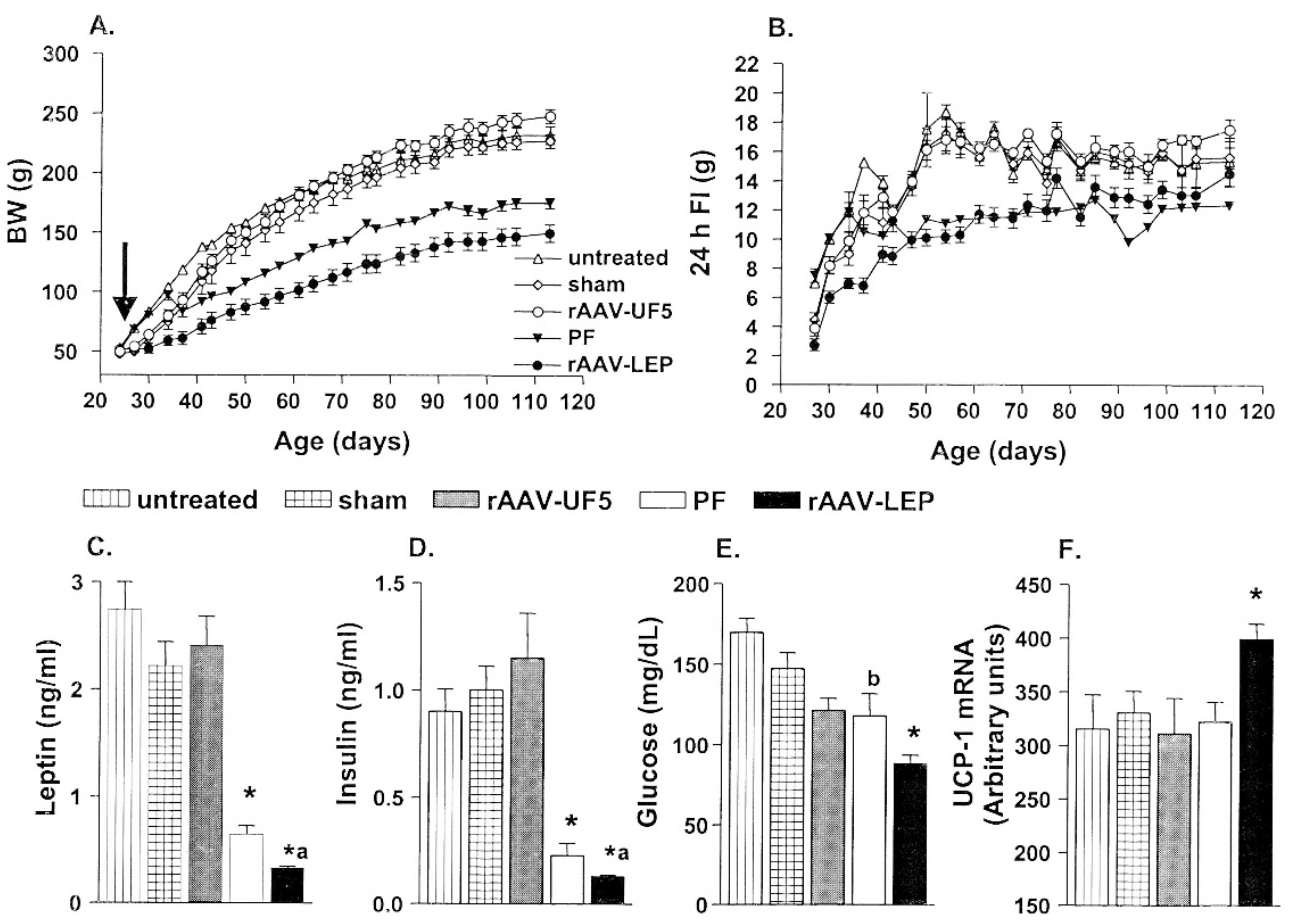

Figure 3. Effects of icv rAAV-lep injection on d 24 on BW $(A)$ and FI $(B)$ during $89 \mathrm{~d}$ postinjection in female rats (age $113 \mathrm{~d})$. Serum leptin $(C)$, insulin $(D)$, glucose $(E)$, and BAT UCP-1 mRNA expression $(F)$ at 89 d postinjection. ${ }^{\mathrm{a}} p<0.05 v s$ pairfed group; ${ }^{\mathrm{b}} p<0.05 v s$ untreated group; ${ }^{*} p<0.001 v s$ untreated, sham, and rAAV-UF5-treated controls. 

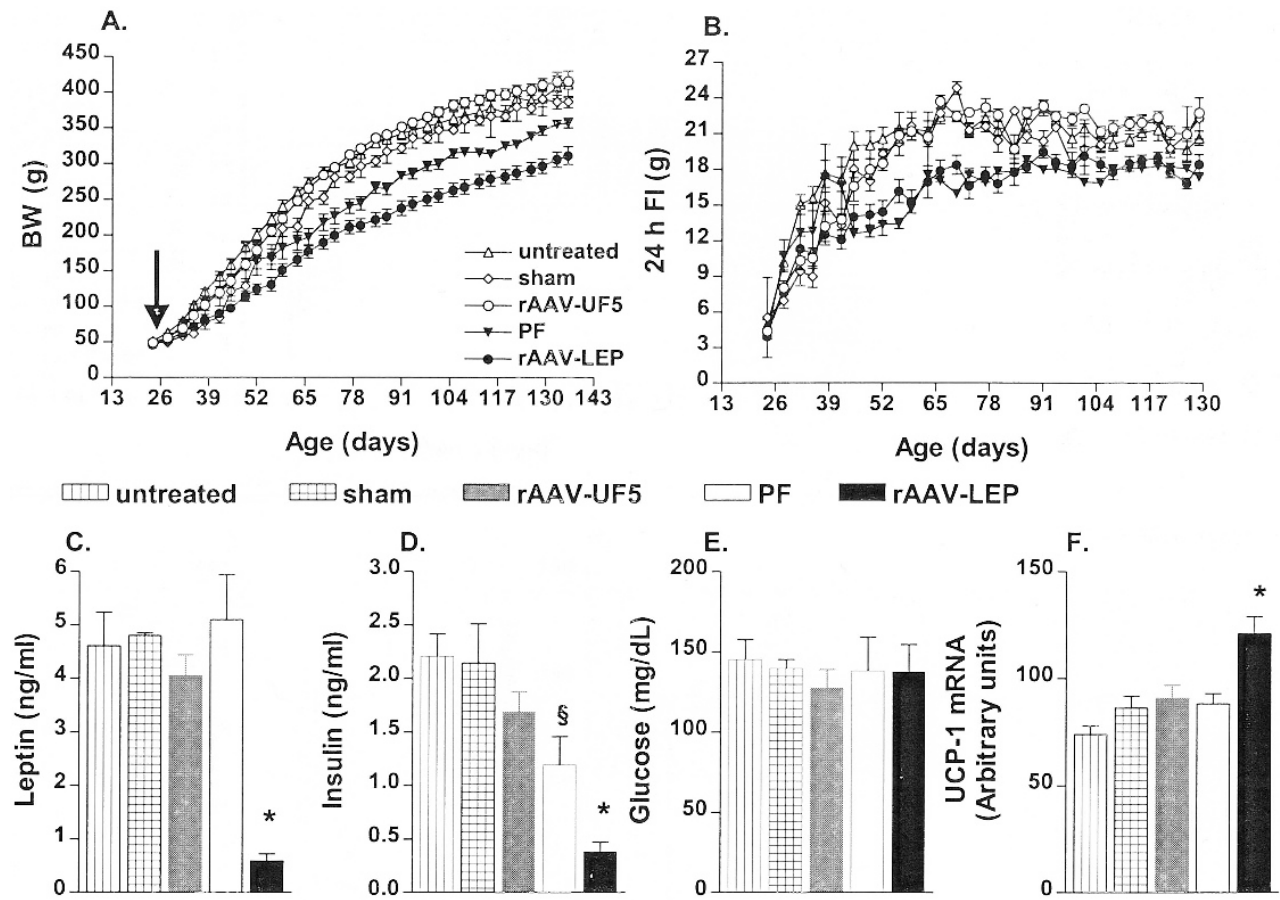

Figure 4. Effects of icv rAAV-lep injection on d 24 in male rats on BW $(A)$ and FI $(B)$ during $111 \mathrm{~d}$ postinjection (age $135 \mathrm{~d})$. Serum leptin $(C)$, insulin $(D)$, glucose $(E)$, and UCP-1 mRNA expression $(F)$ in male rats at $111 \mathrm{~d}$ postinjection. ${ }^{*} p<0.001 v s$ untreated, sham, and rAAV-UF5 controls; $\$ p<0.05 v s$ untreated group.

trast, serum leptin was unchanged and insulin levels were only slightly altered in PF male rats. In rAAV-lep-treated male rats, serum glucose levels were in the range seen in control and PF groups, despite the drastic reduction in serum insulin. In male rats, rAAV-lep treatment also enhanced BAT UCP-1 mRNA expression over that observed in the control groups and the PF group.

Whereas serum FFA were reduced (Table $1, p<0.001$ ), serum ghrelin levels were elevated in both male and female rats after rAAV-lep injection on d 24 (Table 1). As reported previously (29), PF resulted in significantly higher FFA levels both in female and male rats, but serum ghrelin levels were elevated only in PF males and not in PF females.

\section{Effect of rAAV-lep Injection on the Timing of Vaginal Opening and Reproductive Cycles}

Between d 24 and 41 of age, the reduction in FI and BW failed to affect the timing of the onset of sexual maturation (Table 2). In the control as well as in rAAV-lep-treated rats, vaginal opening occurred between 35 and $41 \mathrm{~d}$ of age, as reported previously $(39,40)$. Although pair-feeding rats the amount equivalent to that consumed by rAAV-lep-treated rats decreased weight significantly less than that evoked by rAAVlep treatment, it did not affect the timing of vaginal opening.

The impact on occurrence of regular estrous cycles subsequent to vaginal opening, as monitored at various intervals,

Table 2. Effect of rAAV-LEP injection on the time of the vaginal opening and the length of the estrous cycle

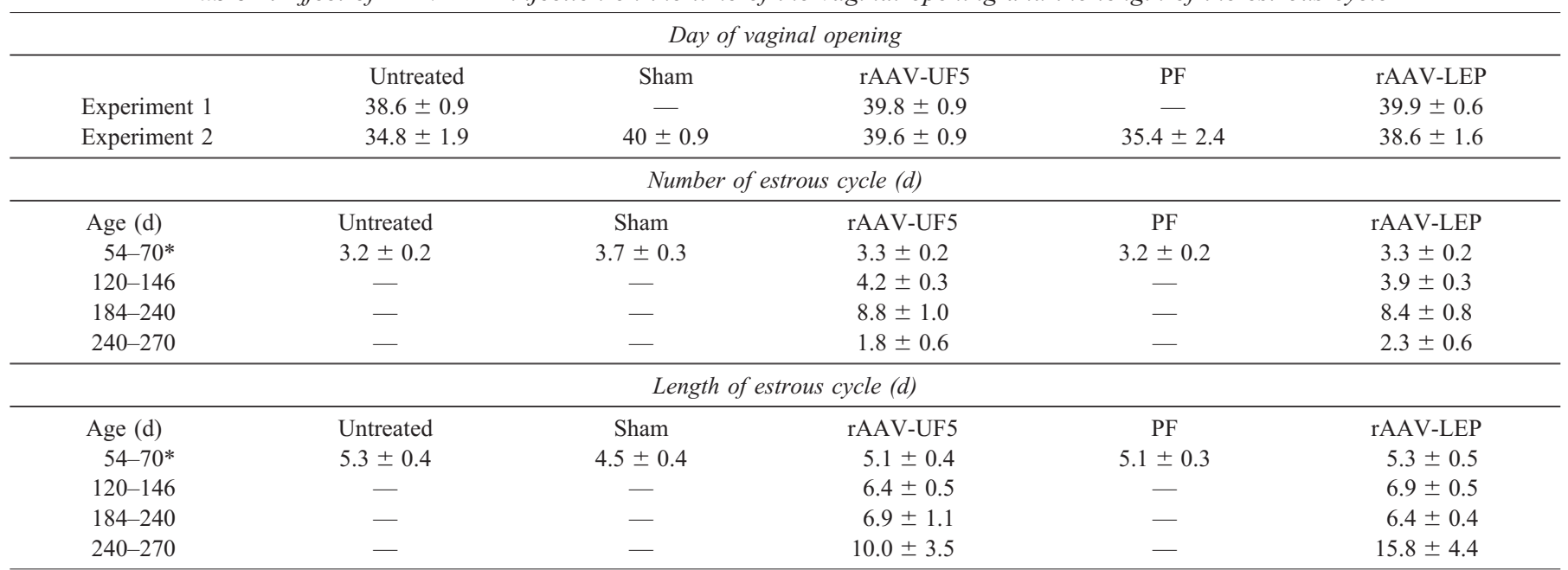

* Data on number of estrous cycles (d) and length of estrous cycles (d) collected during age 54-70 from experiments 1 and 2 were combined. 
showed that the number and duration of estrous cycles were similar in rAAV-lep group and all control groups and PF rats. Also, as expected (46), estrous cycle length increased with age.

\section{Effects of rAAV-lep Injection on Gene Expression of Hypothalamic Peptides Involved in Weight Homeostasis}

The effects of prepubertal rAAV-lep injection on NPY, $A G R P$, and POMC mRNA expression in the hypothalamic ARC in adults are summarized in Figures 5 and 6. NPY but not $A G R P$ mRNA expression was significantly decreased in the hypothalamic ARC of rAAV-injected compared with control groups at $294 \mathrm{~d}(p<0.05$, experiment 1, Figs. 5 and 6$)$ and $89 \mathrm{~d}$ postinjection (experiment 2, Fig. 6). In contrast, $P O M C$ mRNA expression was enhanced in the hypothalamic ARC relative to controls in both experiments $(p<0.05$, Figs. 5 and $6)$. Restriction of food intake by pair-feeding in short- and long-term experiments elicited opposite effects on neuropeptide expression. In PF rats, $N P Y$ mRNA expression increased and $P O M C$ mRNA decreased compared with that found in untreated and rAAV-UF5 rats fed chow ad libitum $(p<0.05)$. In addition, $A G R P$ expression was augmented significantly in $\mathrm{PF}$ rats compared with controls and in rAAV-lep-treated rats $(p$ $<0.05)$.

\section{DISCUSSION}

These results show that increased leptin transgene expression in the hypothalamus after administration of one icv injection of rAAV-lep to 24-d-old female and male rats evoked voluntary reduction in food intake and decreased the rate of weight gain during the entire pubertal and postpubertal periods of observation, lasting as long as $10 \mathrm{mo}$ (experiment 1 ). To the best of our knowledge, this is the first report of a long-lasting weight suppression by central leptin gene therapy initiated prepubertally. These findings complement the reported effectiveness of central rAAV-lep therapy in adult rats to produce sustained suppression of the age-dependent weight gain for 6 mo duration of experiment in rats consuming regular rat chow $(11 \mathrm{Kcal} \%)(24,25)$ and also the rapid weight gain and obesity in rats consuming a high-fat diet (45 Kcal \%) (15).

Serum leptin concentrations were drastically reduced in rAAV-lep-treated rats in this study and in adult rats consuming regular rat chow or high-fat diet $(15,24,25)$. Because shifts in leptin concentrations are reported to occur in direct proportion to fat depots in rodents and humans $(1-3,11-13)$, these low leptin levels, together with reduced adipose tissue-derived FFA, document a loss of fat. Leptin administration either systemically or centrally for short periods decreased adiposity without affecting lean body mass in leptin-deficient $o b / o b$ mice and in normal outbred adult rodents (1-3). Central rAAV-lep therapy in adult rats also markedly decreased adiposity for extended periods without affecting lean tissue mass (25). Although not specifically analyzed in the current investigation, the possibility of prepubertal rAAV-lep treatment affecting lean tissue mass growth in freely feeding rats is quite remote.

Maintenance of reduced weight over extended periods most likely resulted from reduced energy intake along with increased thermogenic energy expenditure, possibly in conjunction with other sympathetic nervous system-driven energy disposition mechanisms $(1,2,5)$, because an equivalent reduction in energy consumption alone in PF rats was far less effective in reducing weight. A significant increase in BAT UCP-1 mRNA in response to rAAV-leptin treatment was observed in both male and female rats in the short-term studies.
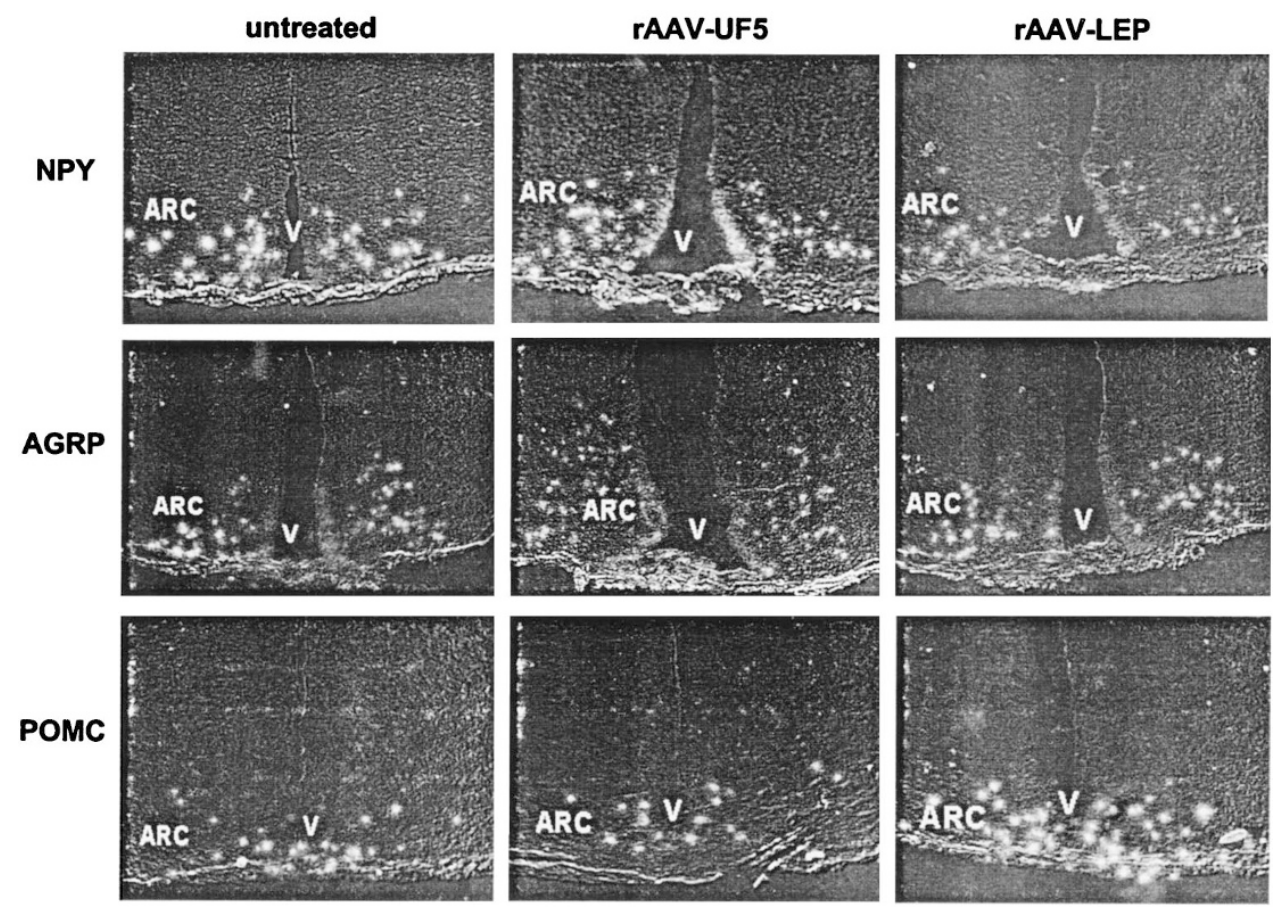

Figure 5. Representative microphotographs of NPY, AGRP and POMC mRNA expression in the ARC of untreated, rAAV-UF5, and rAAV-lep at $294 \mathrm{~d}$ postinjection (experiment 1). $\mathrm{V}$, third ventricle. 

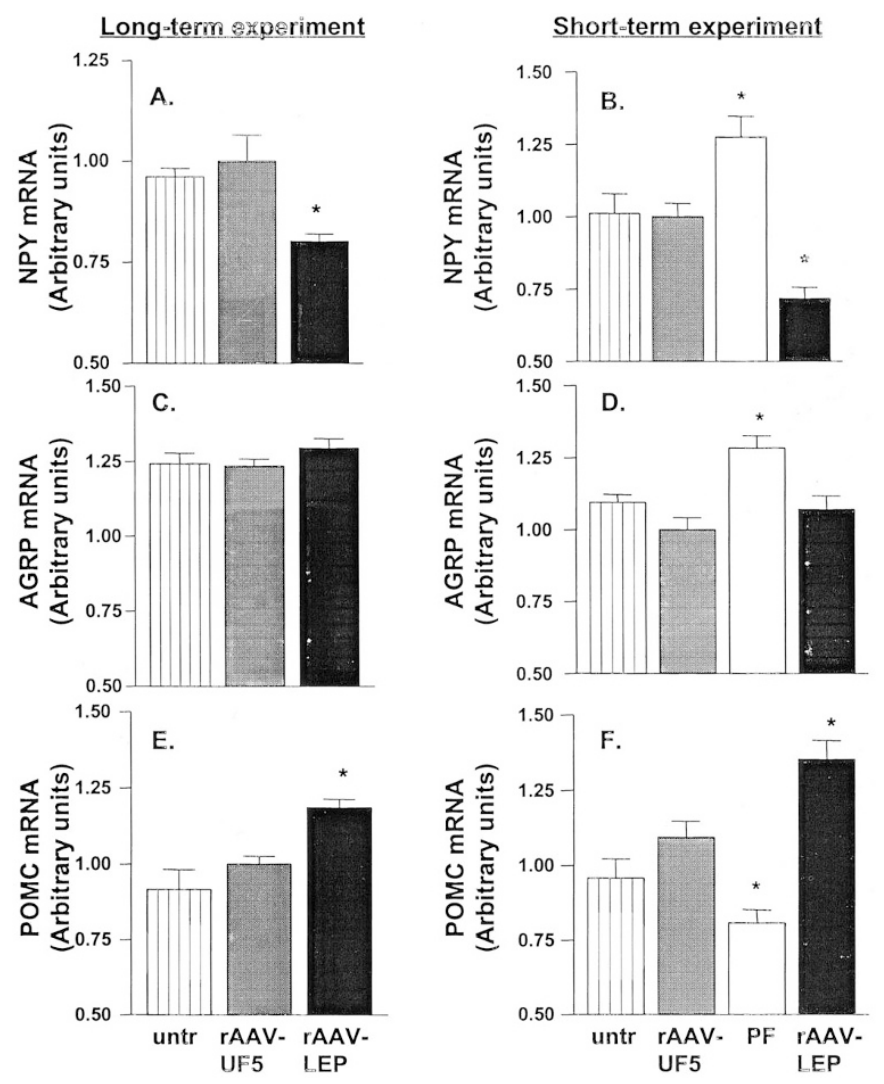

Figure 6. Effects of icv rAAV-lep treatment on NPY, AGRP, and POMC in female rats at $294 \mathrm{~d}$ (experiment $1, A, C, E$ ) and $89 \mathrm{~d}$ post-treatment (experiment $2, B, D, F)$. ${ }^{*} p<0.05 v s$ all the groups.

This observation, along with analogous findings in adult rats $(24,25)$, is consistent with the inference that leptin overexpression in the hypothalamus suppresses weight gain in a manner quite similar to that reported after leptin injections for short periods in obese $o b / o b$ mice and outbred normal rodents $(1-3,47)$. A new finding of the current study is that BAT UCP-1 mRNA was unchanged despite reduced food intake in older rats. This dichotomy, not apparent in adult rats observed for 6 mo $(15,24,25)$, raises the intriguing possibility that the ability of hypothalamic leptin to suppress food intake is retained longer than its ability to augment energy expenditure, and that reduced energy consumption alone, at some time point in the postinjection period, can sustain low weight in older rats. The widely reported, age-related diminution in energy expenditure in rodents and humans (48) conforms to this possibility. Affirmation of our inference of increased energy expenditure, as reflected by BAT UCP1 mRNA, by direct caloimetry and characterization of the timing of onset as well as cellular and molecular basis of dichotomy in these two age-dependent central effects of leptin are underway.

That suppression of weight gain and appetite is a consequence of the relentless effects of sustained leptin overexpression in the hypothalamus is supported by the observation of increased leptin mRNA expression for $6 \mathrm{wk}$ postinjection in adult rats (24) and for 10 mo postinjection in this study. Additionally, we have reported immunocytochemical localization of GFP, transduced from the control rAAV vector, in several hypothalamic sites previously implicated in weight homeostasis $(24,25)$. Because peripheral leptin levels were drastically reduced in rAAV-lep-treated rats, suppression of food intake and augmented energy expenditure was due to the paracrine/autocrine action of locally produced leptin. Our findings clearly demonstrate a sustained weight-reducing effect of ectopic leptin into postpubertal period by a single central injection of rAAV-lep vector to prepubertal rats. This lack of insensitivity to centrally produced leptin for long periods contrasts with the well-known, rapid, age-related development of resistance to rising peripheral leptin, resulting in a loss of leptin's ability to inhibit weight gain and food intake (8-10). Seemingly, the age-related central leptin insufficiency results from defective transport of peripheral leptin to the hypothalamus and not the insensitivity of central targets to leptin itself, as advocated earlier (16-19, 24, 25).

In leptin-deficient obese $o b / o b$ mice and humans, leptin replacement restored reproductive cyclicity $(1-3,49)$. Daily injections of leptin to normal outbred mice in the prepubertal period accelerated the onset of puberty $(35,36)$, however, subsequent studies failed to replicate these findings $(37,38)$. Leptin replacement prevented the delay in vaginal opening induced by severe caloric restriction either by fasting or an enforced severe reduction in caloric intake $(>60 \%)$, paradigms that markedly decrease circulating leptin levels and weight (37, $39,40)$. Thus, a permissive role for leptin in sexual maturation under normal conditions and a facilitatory role under severe caloric deficits is possible. In our experimental design, a reduction in caloric intake of about $22-31 \%$ during the prepubertal period and of about 19-25\% postpubertally, either voluntarily, as in rAAV-lep-treated rats, or enforced, as in PF rats, affected neither the timing of vaginal opening nor the subsequent occurrence of regular estrous cycles. Also, the agedependent reduction in number of estrous cycles and an increase in the duration of estrous cycles (46) was similar in control rats that displayed high circulating leptin and in AAVlep-injected rats with drastically diminished leptin levels. An important new outcome of our study is that the effects of voluntary or enforced reduced caloric intake on endocrine and neuroendocrine control of sexual maturation and reproductive cycles are different from those produced by fasting, a higher magnitude of caloric restriction $(40,41)$.

An analysis of both the short- and long-term impact of hypothalamic leptin overexpression on two functionally opposing, interconnected, appetite-regulating peptidergic neurons that express the biologically relevant long form of the leptin receptor (3-5) provides a neural basis for the sustained suppression of appetite, weight gain, and adiposity. The sustained decrease in NPY mRNA expression in the ARC implies an attenuated release of the appetite-stimulating neuropeptide in the PVN $(5,20)$. A concurrent increase in ARC POMC gene expression suggests enhanced release of the POMC-derived appetite inhibiting $\alpha$-MSH in the PVN $(1,2,5,20)$. Consequently, this dual hypothalamic control on weight homeostasis, mediated by PVN targets, can account for the overall sustained reduction in motivational drive for food in rAAV-lep-injected rats. Similar effects on these two functionally opposing hypothalamic appetite-regulating signals were induced for $6 \mathrm{wk}$ by 
rAAV-lep treatment in adult rats with reduced energy consumption (24). The current study extends these findings to show that leptin overexpression locally in the hypothalamus continues to exert similar effects on NPY and POMC systems for as long as 10 mo duration of the experiment.

AGRP, an orexigenic peptidergic signal coexpressed with NPY in the ARC neurons, stimulates feeding by antagonizing the action of $\alpha$-MSH at MC4 receptors in the PVN $(5,50)$. In this and our previous study (24), leptin transgene overexpression in the hypothalamus failed to affect ARC AGRP mRNA expression. In several other experimental paradigms, relatively negligible participation of AGRP in energy homeostasis has been reported (51). Our findings are in accord with the idea that AGRP signaling may not play a role in the current experimental design, and that locally produced leptin is capable of differentially modulating gene transcription in NPY and AGRP coexpressing neurons in the ARC. Inasmuch as several genes, in addition to $N P Y$ and $P O M C$, play a role in the hypothalamic integration of energy homeostasis (5), it is likely that leptin overexpression in the hypothalamus may engage any one or more of these genes, in concert with NPYergic and melanocortin signalings, to produce a sustained appetite and body weight reduction.

There are three additional new outcomes of this study. First, leptin overexpression in the hypothalamus increased circulating ghrelin levels in younger female and male rats but not in older female rats. Second, this increase in serum ghrelin does not appear to be stimulated by reduced food intake because PF rats failed to display a similar consistent increase in this and the previous study (15). Although the factors responsible for increasing the release of ghrelin from the stomach $(31,32)$ are unknown at present, our results suggest that the stimulatory effects of ghrelin on appetite (32) were blocked by the robust anorectic effects of leptin overexpression in the hypothalamus. Furthermore, in older rAAV-lep-injected female rats, neither ghrelin levels nor BAT UCP1 mRNA expression were augmented. Whether impaired neural relay of information from the hypothalamus to peripheral targets alone or together with an age-dependent diminution in target responsiveness underlie these deficits remains to be ascertained.

Third, serum insulin levels were consistently and markedly reduced after $\mathrm{rAAV}$-lep injection, a response accompanied by only a slight reduction in serum glucose in female rats in these and previous studies in female rats $(15,24,25)$. In the current study, we find that serum glucose was unchanged in male rats. The decreases in serum insulin were consistently greater than those produced by restricted feeding in PF rats in these studies. Apparently, central leptin action effectively blocks the decrease in insulin sensitivity evident in control rats showing high serum insulin levels concomitant with normoglycemia. A similar blockade of the rapid development of insulin insensitivity was obtained in response to icv rAAV-lep in adult rats consuming either normal rat chow or high-fat diet $(15,24,25)$. Low circulating insulin levels in association with diminished adiposity have been reported extensively $(28,29)$. It is plausible that an independent central action of leptin decreased pancreatic insulin release. Although leptin replacement in leptindeficient obese $o b / o b$ mice suppressed peripheral insulin levels
$(52,53)$, the role of peripheral leptin in regulating insulin release directly from pancreas in normal outbred rodents is controversial $(28,29,54,55)$. Furthermore, it was shown recently that peripheral hyperleptinemia was rendered ineffective in depleting fat and suppressing hyperinsulinemia in rats bearing lesions in the ventromedial hypothalamus that disrupted the outflow of information from the hypothalamus (56, 57). Seemingly in agreement with previous reports $(15,24,23)$, the effects of peripheral hyperleptinemia to inhibit pancreatic insulin release and deplete fat are mediated centrally by mechanisms located in the hypothalamus.

In summary, these results show for the first time that one central injection of rAAV encoding leptin in prepubertal rats can transduce leptin transgene overexpression for $10 \mathrm{mo}$, the duration of the experiment. This persistent transgene overexpression decreases postpubertal weight gain accompanied by reduction in food intake, adiposity, and serum insulin and FFA. Suppression of weight gain and appetite apparently resulted from the relentless effects of leptin overexpression on hypothalamic genes regulating appetite. The increase in nonshivering thermogenic energy expenditure and plasma ghrelin levels, however, waned with age. Thus, central leptin gene therapy is a novel therapy to control postpubertal weight gain and adiposity for extended period in rodents and may be a therapeutic modality to ameliorate pediatric obesity.

Acknowledgments. The authors thank Dr. N. Muzyczka, Director of the University of Florida Gene Therapy Center, for assistance in preparation of viral vectors. We also thank Ms. Sandra Clark for assistance with word processing.

\section{REFERENCES}

1. Friedman JM, Halaas JL 1998 Leptin and the regulation of body weight in mammals. Nature 395:763-770

2. Spiegelman BM, Flier JS 2001 Obesity and the regulation of energy balance. Cell 104:531-543

3. Ahima RS, Saper CB, Flier JS, Elmquist JK 2000 Leptin regulation of neuroendocrine systems. Front Neuroendocrinol 21:263-307

4. Morash B, Li A, Murphy PR, Wilkinson M, Ur E 1999 Leptin gene expression in the brain and pituitary gland. Endocrinology 140:5995-5998

5. Kalra SP, Dube MG, Pu S, Xu B, Horvath TL, Kalra PS 1999 Interacting appetiteregulating pathways in the hypothalamic regulation of body weight. Endocr Rev 20:68-100

6. Lowell BB, Spiegelman BM 2000 Towards a molecular understanding of adaptive thermogenesis. Nature 404:652-660

7. Himms-Hagens J 1991 Neural control of brown adipose tissue thermogenesis, hypertrophy, and atrophy. Front Neuroendocrinol 12:38-93

8. Wolden-Hanson T, Marck BT, Smith L, Matsumoto AM 1999 Cross-sectional and longitudinal analysis of age-associated changes in body composition of male Brown Norway rats: association of serum leptin levels with peripheral adiposity. J Gerontol A Biol Sci Med Sci 54:B99-B107

9. Pu S, Dube MG, Kalra PS, Kalra SP 2000 Regulation of leptin secretion: effects of aging on daily patterns of serum leptin and food consumption. Regul Pept 92:107-111

10. Dhillon H, Ge Y, Minter RM, Prima V, Moldawer LL, Muzyczka N, Zolotukhin S, Kalra PS, Kalra SP 2000 Long-term differential modulation of genes encoding orexigenic and anorexigenic peptides by leptin delivered by rAAV vector in ob/ob mice. Relationship with body weight change. Regul Pept 92:97-105

11. Considine RV, Sinha MK, Heiman ML, Kriauciunas A, Stephens TW, Nyce MR, Ohannesian JP, Marco CC, Mckee LJ, Bauer TL, Caro JF 1996 Serum immunoreactive-leptin concentrations in normal-weight and obese humans. N Engl J Med 334:292-295

12. Frederich RC, Hamann A, Anderson S, Lollmann B, Lowell BB, Flier JS 1995 Leptin levels reflect body lipid content in mice: evidence for diet-induced resistance to leptin action. Nat Med 1:1311-1314

13. Maffei M, Halaas J, Ravussin E, Pratley RE, Lee GH, Zhang Y, Fei H, Kim S, Lallone R, Ranganathan S, Kern PA 1995 Leptin levels in human and rodent: measurement of plasma leptin and ob RNA in obese and weight-reduced subjects. Nat Med $1: 1155-1161$ 
14. Heymsfield SB, Greenberg AS, Fujioka K, Dixon RM, Kushner R, Hunt T, Lubina JA, Patane J, Self B, Hunt P, Mccamish M 1999 Recombinant leptin for weight loss in obese and lean adults: a randomized, controlled, dose-escalation trial. JAMA 282:1568-1575

15. Dube MG, Beretta E, Dhillon H, Ueno N, Kalra PS, Kalra SP 2002 Central leptin gene therapy blocks high fat diet-induced weight gain, hyperleptinemia and hyperinsulinemia: effects on serum ghrelin levels. Diabetes (in press)

16. Kastin AJ, Pan W 2000 Dynamic regulation of leptin entry into brain by the blood-brain barrier. Regul Pept 92:37-43

17. Banks WA, Dipalma CR, Farrell CL 1999 Impaired transport of leptin across the blood-brain barrier in obesity. Peptides 20:1341-1345

18. Burguera B, Couce ME, Curran GL, Jensen MD, Lloyd RV, Cleary MP, Poduslo JF 2000 Obesity is associated with a decreased leptin transport across the blood-brain barrier in rats. Diabetes 49:1219-1223

19. Van Heek M, Compton DS, France CF, Tedesco RP, Fawzi AB, Graziano MP, Sybertz EJ, Strader CD, Davis Jr HR 1997 Diet-induced obese mice develop peripheral, but not central, resistance to leptin. J Clin Invest 99:385-390

20. Kalra 2001 Circumventing leptin resistance for weight control. Proc Natl Acad Sci U S A 98:4279-4281

21. Kalra SP, Kalra PS 2001 Viral vectors as probes to decipher brain circuitry for weight control. Trends Endocrinol Metab 12:377-378

22. Friedmann T 1999 The Origins, Evolution, and Directions of Human Gene Therapy. Cold Spring Harbor Laboratory Press, Cold Spring Harbor, NY

23. Samulski RJ, Sally M, Muzyczka N 1999 Adeno-associated viral vectors. In: Friedman T (ed) The Development of Human Gene Therapy. Cold Spring Harbor Laboratory Press, Cold Spring Harbor, NY, pp 131-172

24. Dhillon H, Kalra SP, Kalra PS 2001 Dose-dependent effects of central leptin gene therapy on genes that regulate body weight and appetite in the hypothalamus. Mol Ther 4:139-145

25. Dhillon H, Kalra SP, Prima V, Zolotukhin S, Scarpace PJ, Moldawer LL, Muzyczka N, Kalra PS 2001 Central leptin gene therapy suppresses body weight gain, adiposity and serum insulin without affecting food consumption in normal rats: a long-term study. Regul Pept 99:69-77

26. Kopelman PG 2000 Obesity as a medical problem. Nature 404:635-643

27. Yanovski JA 2001 Pediatric obesity. Rev Endocr Metab Disord 2:371-383

28. Kieffer TJ, Habener JF 2000 The adipoinsular axis: effects of leptin on pancreatic beta-cells. Am J Physiol Endocrinol Metab 278:E1-E14

29. Unger RH 2000 Leptin physiology: a second look. Regul Pept 92:87-95

30. Mizuno TM, Mobbs CV 1999 Hypothalamic agouti-related protein messenger ribonucleic acid is inhibited by leptin and stimulated by fasting. Endocrinology 140:814817

31. Inui A 2001 Ghrelin: an orexigenic and somatotrophic signal from the stomach. Nat Rev Neurosci 2:551-560

32. Tschop M, Smiley DL, Heiman ML 2000 Ghrelin induces adiposity in rodents. Nature 407:908-913

33. Horvath TL, Diano S, Sotonyi P, Heiman M, Tschop M 2001 Minireview: ghrelin and the regulation of energy balance-a hypothalamic perspective. Endocrinology 142:4163-4169

34. Bagnasco M, Kalra PS, Kalra SP 2002 Ghrelin and leptin pulse discharge in fed and fasted rats. Endocrinology 143:726-729

35. Chehab FF, Mounzih K, Lu R, Lim ME 1997 Early onset of reproductive function in normal female mice treated with leptin. Science 275:88-90

36. Ahima RS, Dushay J, Flier SN, Prabakaran D, Flier JS 1997 Leptin accelerates the onset of puberty in normal female mice. J Clin Invest 99:391-395
37. Cunningham MJ, Clifton DK, Steiner RA 1999 Leptin's actions on the reproductive axis: perspectives and mechanisms. Biol Reprod 60:216-222

38. Bronson FH 2001 Puberty in female mice is not associated with increases in either body fat or leptin. Endocrinology 142:4758-4761

39. Gruaz NM, Lalaoui M, Pierroz DD, Englaro P, Sizonenko PC, Blum WF, Aubert ML 1998 Chronic administration of leptin into the lateral ventricle induces sexual maturation in severely food-restricted female rats. J Neuroendocrinol 10:627-633

40. Cheung CC, Clifton DK, Steiner RA 2000 Perspectives on leptin's role as a metabolic signal for the onset of puberty. Front Horm Res 26:87-105

41. Kalra SP, Kalra PS 1996 Nutritional infertility: the role of the interconnected hypothalamic neuropeptide Y-galanin-opioid network. Front Neuroendocrinol 17:371-401

42. Caprio M, Fabbrini E, Isidori AM, Aversa A, Fabbri A 2001 Leptin in reproduction. Trends Endocrinol Metab 12:65-72

43. Hauswirth WW, Lewin AS, Zolotukhin S, Muzyczka N 2000 Production and purification of recombinant adeno-associated virus. Methods Enzymol 316:743-761

44. Kalra SP, Kalra PS 1974 Temporal interrelationships among circulating levels of estradiol, progesterone and LH during the rat estrous cycle: effects of exogenous progesterone. Endocrinology 95:1711-1718

45. Kalra SP, Kalra PS 1983 Neural regulation of luteinizing hormone secretion in the rat Endocr Rev 4:311-351

46. Wise PM, Krajnak KM, Kashon ML 1996 Menopause: the aging of multiple pacemakers. Science 273:67-70

47. Scarpace PJ, Matheny M, Pollock BH, Tumer N 1997 Leptin increases uncoupling protein expression and energy expenditure. Am J Physiol 273(1 Pt 1):E226-E230

48. McDonald RB, Horwitz BA 1999 Brown adipose tissue thermogenesis during aging and senescence. J Bioenerg Biomembr 31:507-516

49. Farooqi IS, Jebb SA, Langmack G, Lawrence E, Cheetham CH, Prentice AM, Hughes IA, McCamish MA, O'Rahilly S 1999 Effects of recombinant leptin therapy in a child with congenital leptin deficiency. N Engl J Med 341:879-884

50. Hahn TM, Breininger JF, Baskin DG, Schwartz MW 1998 Coexpression of AGRP and NPY in fasting-activated hypothalamic neurons. Nat Neurosci 1:271-272

51. Korner J, Savontaus E, Chua SC, Leibel RL, Wardlaw SL 2001 Leptin regulation of AgrP and NPY mRNA in the rat hypothalamus. J Neuroendocrinol 13:959-966

52. Murphy JE, Zhou S, Giese K, Williams LT, Escobedo JA, Dwarki VJ 1997 Longterm correction of obesity and diabetes in genetically obese mice by a single intramuscular injection of recombinant adeno-associated virus encoding mouse leptin. Proc Natl Acad Sci U S A 94:13921-13926

53. Muzzin P, Eisensmith RC, Copeland KC, Woo SL 1996 Correction of obesity and diabetes in genetically obese mice by leptin gene therapy. Proc Natl Acad Sci U S A 93:14804-14808

54. Seufert J, Kieffer TJ, Habener JF 1999 Leptin inhibits insulin gene transcription and reverses hyperinsulinemia in leptin-deficient ob/ob mice. Proc Natl Acad Sci U S A 96:674-679

55. Mizuno A, Murakami T, Otani S, Kuwajima M, Shima K 1998 Leptin affects pancreatic endocrine functions through the sympathetic nervous system. Endocrinology 139:3863-3870

56. Chen G, Koyama K, Yuan X, Lee Y, Zhou YT, O'Doherty R, Newgard CB, Unger RH 1996 Disappearance of body fat in normal rats induced by adenovirus-mediated leptin gene therapy. Proc Natl Acad Sci U S A 93:14795-14799

57. Koyama K, Shimabukuro M, Chen G, Wang MY, Lee Y, Kalra PS, Dube MG, Kalra SP, Newgard CB, Unger RH 1998 Resistance to adenovirally induced hyperleptinemia in rats. Comparison of ventromedial hypothalamic lesions and mutated leptin receptors. J Clin Invest 102:728-733 